\title{
SMART HOME USING ANDRIOD APPLICATION
}

\author{
Dhawade Pooja $\mathbf{J}^{1}$, Lathkar Y.V ${ }^{2}$, Date Purushottam $\mathbf{B}^{\mathbf{3}}$ \\ ${ }^{1}$ Student, Electronics \& Telecommunication Department, IOK, COE Pune, Maharashtra, India \\ ${ }^{2}$ Assit.Prof, Electronics \& Telecommunication Department, IOK COE Pune, Maharashtra, India \\ ${ }^{3}$ Student, Electronics \& Telecommunication Department, IOK COE Pune, Maharashtra, India
}

\begin{abstract}
These Technology advancements have made the implementation of embedded systems within home appliances. Automation of the surrounding environment of a modern human being allows increasing his work efficiency and comfort. This paper presents a technology where the user controls the devices through smart phones. Smart Home System has been designed for mobile phones having Android platform to enable Wi-Fi network which is interfaced with AVR Microcontroller which controls a number of home appliances like lights, fans and many more using suitable on/off switching devices. Android provides access to a wide range of useful libraries and tools that can be used to build rich applications. Wi-Fi is an open standard specification for a radio frequency $(R F)$ based wireless connectivity technology. The controlling device of the whole system is an AVR Microcontroller. The controller acts accordingly to switch connected home appliances.
\end{abstract}

Keywords: Smart Home, Android Mobile Phone, Wi-Fi, AVR Microcontroller.

\section{INTRODUCTION}

In nowadays, we must make use of various high-tech tools and equipments to get our jobs done and make our life comfortable. And the mobile phone is the inseparable part of human lives today. With the help of mobile phones human can done many works related to their civil life.at todays repaired technology the mobile phone is also become smart one. With the help of this smart gadget we can make our home smart one. Some products are commercially available in market which allows home appliances controlling through internet, GSM, DTMF, Bluetooth, RFID, and Zigbee. But it lacks the true sense of real mobility, security and some limited range of connectivity. We proposed a new technology so that the ordinary services of the mobile phones can be used to communicate with and control the home appliances. Here, the switch board of our regular use is replacing by Wi-Fi module which will communicate with AVR microcontroller and the android based smart phone. The home appliances monitoring and controlling is done wirelessly through Android smart phone using the $\mathrm{Wi}-\mathrm{Fi}$ feature present in it. Android is a healthy array of connectivity options, including Wi-Fi, Bluetooth, and wireless data over a cellular connection. The advantage of controlling mechanism is the devices controlling and monitoring is available in two modes that is automatic mode and user mode. In user mode the controlling is done with instruction given by android based smart phone and in case the user is not present at home to control the required appliance the present home owner can use the automatic mode to control and monitor the appliance. The important part of this technique is that the appliances run on single processor and produce required output. Here all the devices which are to be controlled are connected to the AVR Microcontroller and suitable switching devices like triac. There are four triac connected and are controlled automatically for different appliances like light on-off, fan on-off and speed control, Temperature and light intensity can be sensed as well as the PIR sensor can be used for security purpose. New appliances can be added anytime to the system, which provides for the reliability of the system.

\section{SYSTEM OVERVIEW}

Fig 1 illustrates the overall control function of the system. The projected system works using the smartphone application. The smartphone application is nothing but an android application which is the main source for giving the instruction to the $\mathrm{Wi}$ Fi module. The transmitter of Wi-Fi transmits the data given by the application using radio waves technology.

The Wi-Fi works on radio waves technology, as the data to be passed through $\mathrm{Wi}-\mathrm{Fi}$ is converted into the electromagnetic signal which is then sent using the antenna. This signal is received and decoded by the router at the receiving end. This signal is passed to the controller which is nothing but AVR controller.

The AVR further operates the received information and performs operations on the appliances, which are driven by the driver circuitry. So, following are the hardware requirement for the system to be developed. 


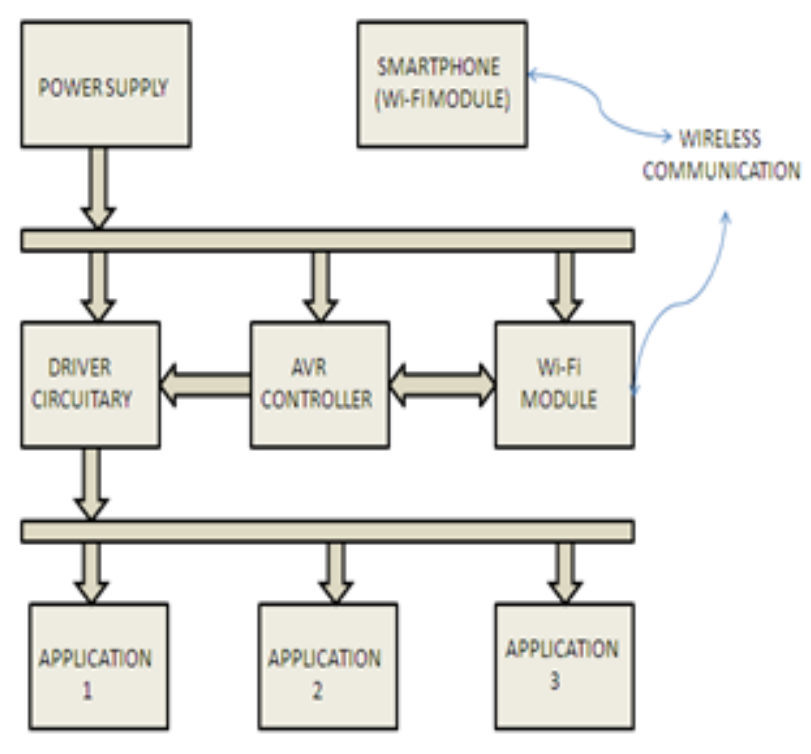

Fig -1: Functional Block Diagram

\subsection{AVR Microcontroller}

Microcontroller used is ATMega16L .It is one of the high performance low power 8 bit microcontroller. Having four PWM channels. Real-time counter with separate oscillator. It has 8-channel, 10bit inbuilt ADC. JTAG interfacing with boundary scan capabilities. It also has $16 \mathrm{~K}$ Bytes in system programmable flash. The Microcontroller having six sleep modes of operation, like Ideal mode, ADC Noise Reduction mode, Power Save Mode, Power Down mode, Standby mode and Extended Standby mode. The Controller operates on 2.7 to $5.5 \mathrm{~V}$, With Speed Grades of 0 to $8 \mathrm{Mhz}$. The Controller having a two special Features, first one is Power-on Reset and Programmable Brown-out Detection and second one is External and Internal Interrupt Sources.

\subsection{Wi-Fi Module}

Wi-Fi is a technology that allows an electronic device to exchange data or connects using microwaves in the $2.4 \mathrm{GHz}$ and $5 \mathrm{GHz}$ bands. The module is based on the Institute of Electrical and Electronics Engineers 802.11 standards. Wi-Fi is more suitable for sensitive applications. It has power saving mechanisms and extended battery life. Support transparent transmission mode as well as multiple network protocols. The Wi-Fi module use is embedded based on the universal serial interface network standard, built-in TCP / IP protocol stack, enabling the user serial port, Ethernet, wireless network (wifi) interface between the conversions. The modules integrate all of the RF components required, removing the need to perform expensive RF design and test. It simply connecting sensors and switches to the module I/O pins or UART interface.

\subsection{Android Application}

Android is a software stack for mobile devices that includes an operating system, middleware and key applications. Android boasts a healthy array of connectivity options including $\mathrm{Wi}-\mathrm{Fi}$, Bluetooth, and wireless data over a cellular connection. Android provides access to a wide range of useful libraries and tools that can be used to build rich applications. In addition, Android includes a full set of tools that have been built from the ground up alongside the platform providing developers with high productivity and deep insight into their applications. [11]

\subsection{Driver Circuitary}

In electrical circuit driver is the circuit component used to control another circuit such as high power transistors, triacs, relays and many other. They are usually used to regulate current flowing through a circuit or is used to control the other factor such as other components and devices in the circuit. The most popular type of voltage regulator IC is the 78XX series, sometimes called the LM78XX series. These voltage regulator combine 17 transistor, three Zener diodes, \& a helpful of resistors into one hand by package with three pins and a heat sink that helps dissipate the excess power consumed by the regulator as it compensates for increases or decreases in current draw to keep the voltage at a constant level. The last two digits of the 78XX ID number indicate the output voltage regulated by the IC. To use a 78XX voltage regulator, you just insert it in series on the positive side of the power supply circuit and connect the ground lead to the negative side. As this shows, it's also a good idea to place a small capacitor after the regulator. The diodes in a bridge rectifier will drop about $3 \mathrm{~V}$ from the transformer output, So you will need a transformer whose secondary delivers at least $11 \mathrm{~V}$ to produce $5 \mathrm{~V}$ of regulated output. $11 \mathrm{~V}$ transformers are rare, but $12 \mathrm{~V}$ transformer is readily available. Thus, a $5 \mathrm{~V}$ regulated power supply starts with a $12 \mathrm{~V}$ ac transformer that delivers $12 \mathrm{~V}$ to the bridge rectifier, which converts the AC to DC And drops the voltage down to about $9 \mathrm{~V} \&$ then delivers the voltage to the filter circuit, which smoothes out the ripples and passes the voltage on to the 7805 voltage regulator, which holds the output voltage at $5 \mathrm{~V}$.

\subsection{Appliances to be controlled}

The appliances which are to be control is the interface with driver circuitry to microcontroller which are wirelessly connected to Wi-Fi. The appliances which are to be controlled is light on-off, controlling the speed of fan as well as on-off. There are three sensors are used one is the temperature sensor which sense different values of temperature. The second sensor is Light -dependent resister sensor is very useful especially in light/dark sensor circuits. Normally the resistance of a sensor is very high, but when they are illuminated with light resistance drops dramatically, allowing current to pass through it. The third sensor is Passive Infrared Sensor which is 
a device that detects motion by measuring changes in the infrared levels emitted by surrounding objects. This motion can be detected by checking for a high signal on a single input output pin.

\section{ACTIVITY DIAGRAM}

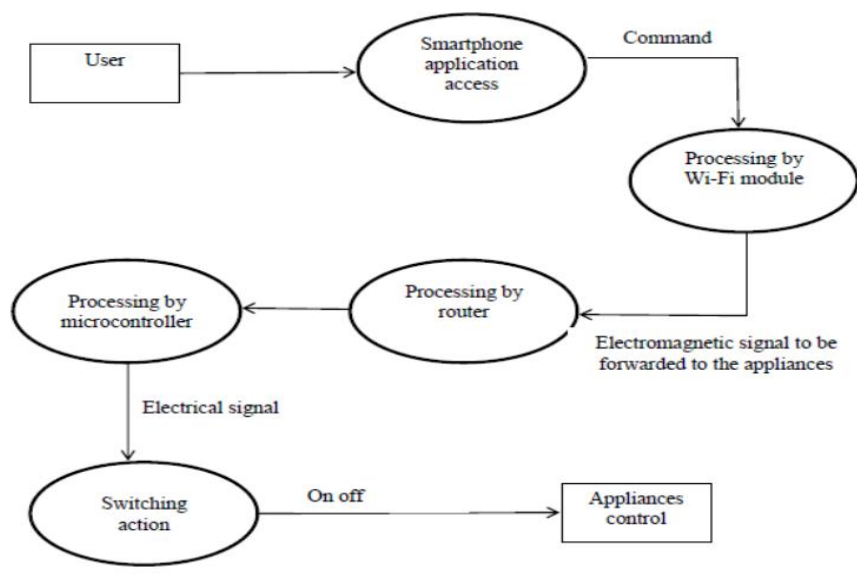

Fig -2: Activity diagram

The Fig. 2 Shown above represents the activity diagram of system. It shows the process of flow of activities. Initially there are two modes of operations one is user mode and second is automatic mode. The user can access the smart phone application and gives command to $\mathrm{Wi}-\mathrm{Fi}$ module. The Wi-Fi module can processing router with help of electromagnetic signal which will processing microcontroller. The switching action can be take place with help of driver circuitary. The driver circuitry can control and manage the devices as per there required conditions. Devices can be on-off and senses by the driver circuitry.

\section{CONCLUSIONS}

In this paper presenting a new system is design. There are number of designs are built in this automation field but the this is the system design which are operated in two different conditions either smart phone user present at home or other family members are at home both can be access and control the appliances. The system is implemented not only for limited area but is useful for all required area. As per the point of security there is access code for a Wi-Fi. So the system is easier to use and protected with the help of access code.

\section{ACKNOWLEDGEMENTS}

Any accomplishment requires the effort of many people and this work is no different. I find great pleasure in expressing my deep sense of gratitude towards all those who have made it possible for me to present this work. I would like to express my true sense and sincerest gratitude to Prof. Y. V. Lathkar my guide, for dynamic and valuable guidance and keen interest in my paper work. I am grateful to him for giving me opportunity to publish this work. This paper work is a result of combined efforts put in by my guide and me. I also extend our sincere thanks to Head of Department, Electronics \& Telecommunication, Prof. A. M. Maske and all the staff members who extended the preparatory steps of this paper work. I am also thankful to Prof. D. B. Salunke for showing faith in us and providing required facilities.

\section{REFERENCES}

[1] Mayur Jain," Smart Home System Using Android Mobile Devices", Journal of Computing Technologies Vol 2, Issue 3 ISSN 2278 - 3814

[2] R.Piyare, M.Tazil. "Bluetooth based home automation system using cell phone" IEEE 15th International Symposium on Consumer Electronics, 2011.

[3] K.Tan, T.Lee and C.Yee Soh. "Internet-Based Monitoring of Distributed Control Systems-An Undergraduate Experiment". IEEE Transaction on Education, Vol. 45, No. 2, May 2002.

[4] N. Swamy, O. Kuljaca and F. Lewis. "Internet-Based Educational Control Systems Lab Using Net-meeting". IEEE Transaction on Education, Vol. 45, No. 2, pp.145-151, May 2002.

[5] N. Sriskanthan and Tan Karand. "Bluetooth Based Home Automation System". Journal of Microprocessors and Microsystems, Vol. 26, pp.281289, 2002.

[6] Embedded web server for home appliances : by $\mathrm{Mr}$. Abhishek Vichare, Ms. Shilpa Verma (IJERA) ISSN:2248-9622

[7] Y.R.Dhumal," Green House Automation using Zigbee and Smart Phone", International Journal of Advanced Research in Computer Science and Software Engineering Research Paper, Volume 3, Issue 5, May 2013

[8] Sharon Panth," Home Automation System (HAS) using Android for Mobile Phone", International Journal of Electronics and Computer Science Engineering ISSN2277-1956.

[9] Soyoung Hwang and Donghui Yu," Remote Monitoring and Controlling System Based on ZigBee Networks", International Journal of Software Engineering and Its Applications Vol. 6, No. 3, July, 2012

[10] Sweatha K N," ADVANCE HOME AUTOMATION USING FPGA CONTROLLER, International Journal of Advanced Research in Computer and Communication Engineering Vol. 2, Issue 7, July 2013.

[11] Sooxma Technologies," Google Android operated Smart Home". 